\title{
DEGREE OF SATISFACTION OF THE HIGH-INCOME SEGMENT CUSTOMERS OF THE BANCO DO BRASIL
}

\author{
Bruno Lacerda Macedo, Banco do Brasil, Brazil \\ Jorge Alberto Velloso Saldanha, Universidade Federal Rural do Rio de Janeiro, Brazil
}

$\underline{\text { dx.doi.org/10.18374/EJM-20-1.9 }}$

\begin{abstract}
This study attempts to measure the degree of satisfaction of the high-income segment customers of the Banco do Brasil (BB) regarding the services offered at the Estilo branches in the State of Rio de Janeiro, Brazil. The research was done in two phases. The first phase, of a qualitative approach, was developed to identify the most important attributes for customer satisfaction. The second phase of the research, of a descriptive type, was done by using a structured questionnaire in a sample composed of 400 survey instruments. The results indicate that the customers are satisfied, since the average score for the general rating of services was 8.64 (on a scale of 1 to 10) and all the surveyed attributes obtained a satisfaction average higher than the indifference number. Regarding the degree of importance, the attribute mentioned the most was "trust in the institution". This was also the attribute in which the customers stated to have the highest satisfaction. The research confirmed the existence of a strong correlation between the most important attributes for customer satisfaction and the attributes the customers are the most satisfied with.
\end{abstract}

Keywords: Banking Services, Customer Satisfaction, High-income Segment, Banco do Brasil 